\title{
QUADRINHOS É COISA DE CRIANÇA: \\ CONSIDERAÇÕES SOBRE UM EQUIVOCO \\ DESIMPORTANTE
}

\author{
COMICS ARE KIDS' STUFF: CONSIDERATIONS \\ ABOUT AN UNIMPORTANT MISUNDERSTANDING
}

\section{LOS CÓMICS SON COSAS DE NIÑOS: CONSIDERACIONES SOBRE UN EQUIIVOCO IRRELEVANTE}


RESUMO: Este artigo pretende discutir a associação dos quadrinhos com o universo infantil, seja pela leitura e recepção ou pela compreensão do meio como forma de leitura infantil. Estabeleceu-se uma reflexáo sobre a criança como tema nos quadrinhos e como público alvo de uma indústria.

ABSTRACT: This article intends to discuss the association of comics with the infant universe, either by reading and receiving or by understanding the medium as a form of children's reading. It was established a reflection on the child as a theme in the comics and as an industry target audience.

RESUMEN: Este artículo pretende discutir la asociación de los cómics con el universo infantil, tanto por la lectura y la recepción, como por la comprensión del medio como una forma de la lectura infantil. Se estableció una reflexión sobre el niño como tema en los cómics y como público destinatario de una industria.

PALAVRAS-CHAVE: Quadrinhos; Infância; Literatura Infantil.

KEYWORDS: Comics; Childhood; Children's literature.

PALABRAS CLAVE: Cómics; Infancia; Literatura Infantil.

$\cos$

A compreensão dos quadrinhos como uma leitura infantil compôs, por muito tempo, a concepção do senso comum sobre a natureza do meio. Embora os quadrinhos possam ser vistos como um recurso pedagógico eficiente, e de fato esteve presente na alfabetização de muitos leitores, não é verdade que, em sua totalidade, ele represente uma leitura para crianças. Mesmo nas histórias, hoje associadas ao mundo da criança, em sua gênese, não havia um intento de dirigir-se aos pequenos. Tratou-se de uma mudança gradual dos interesses do meio e da recepçáo dos leitores para o mundo dos produtos direcionados para criança. Este trabalho pretende, assim, suscitar a discussão sobre como os quadrinhos, desde a sua origem, tornaram-se, gradativamente, considerados, por grande parte das pessoas, uma leitura para crianças.

Os quadrinhos nasceram dos jornais e das revistas satíricas, mesclando técnicas da caricatura e contos ilustrados, resultando no que veio a ser a tira de jornal. Surgem, assim, no final do século XIX, as primeiras tiras que, como toda arte nova, experimentavam tanto 
na forma como no tema. Alguns temas tornaram-se recorrentes, como o vagabundo, a família, os funny animals (tiras de animais falantes) e a criança. Cada temática cunhou dentro do universo das tiras seu próprio gênero e tradição. Uma temática muito comum era a criança, originando o que é conhecido pelo meio como kid strip.

$\mathrm{Na}$ era de ouro dos quadrinhos, entre meados de 1890 até o final da década 30, as kid strips multiplicaram-se sobremaneira, dentre as quais podemos citar: Little Jimmy, de James Swinnerton's (1904); The Kin-der-Kids (1906), de Lyonel Feninger's; Freckles and His Friends, de Merrill Blosser's (1915); Reg'lar Fellas, de Gene Byrnes's (1916); Little Mary Mixup, de R. M. Brinkerhoff's (1917); Cap Stubbs and Tippie, de Edwina Dumm's (1918); e Nancy, de Ernie Bushmiller's (1938) (HARVEY, 1998, p. 36). Estão entre as kid strips, séries fundamentais na história das HQs, como The Yellow Kid, de Richard Outcault (1894); The Katzenjammer Kids, de Rudolph Dirks (1897); e Little Nemo in Slumberland, de Winsor McCay (1905). Tais tiras figuram entre as mais influentes séries da época, responsáveis por consolidar os fundamentos não só da linguagem da tira, mas dos quadrinhos como uma arte singular, dotada de uma linguagem própria e única, segundo afirmam muitos estudiosos dos comics como Robert Harvey (1998), Richard Marschall (1989), Santiago García (2012) e Álvaro de Moya (1970).

Apesar de todas trazerem a criança como protagonista, esse painel era composto de uma diversidade de tons. Séries como Buster Brown, do Outcault (1902), e Katzenjammer Kids exploravam uma visão da infância como um lugar de contestação e travessuras, enquanto outras como The Kin-der-kids e Little Nemo in Slumberland demonstravam uma infância capaz de transitar por um universo mais onírico, surreal e dotado de sentidos mais complexos que o humor rápido da travessura.

A grande influência dos quadrinhos norte-americanos protagonizados por crianças foi uma obra de 1865, do alemão Wilhelm Busch, intitulada Max und Moritz. No Brasil, a obra saiu com o título de Juca e Chico e foi traduzida por Olavo Bilac.

Esse livro é comumente posto, pelos teóricos e historiadores dos quadrinhos, como um precursor do gênero. A sequência das imagens compondo uma ação, a interdependência 
entre imagem e texto, e o dinamismo das ilustraçóes o qualificaria já como um quadrinho. (SCHNEIDER, 2011, p. 26).

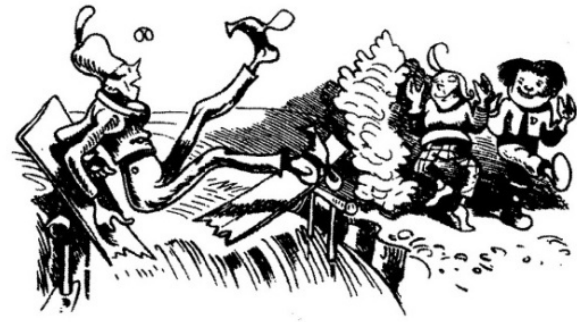

Chega à ponte. Mas... traraque! Quebra-se a tábua. Que baque!

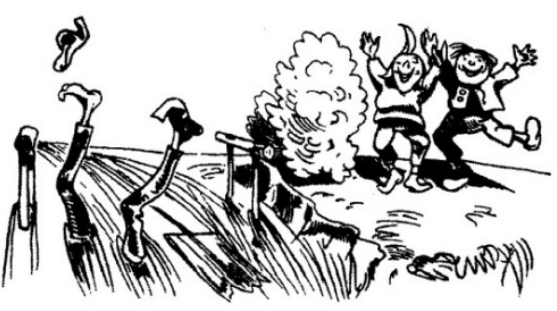

E os dois: "mé! mé! mé!" e Brás Bumba! n'água... Catatraz! Eis justamente que um par

Figura 1: Trecho de Max und Moritz (BUSCH. In. CAMPOS, 2015, p. 190).
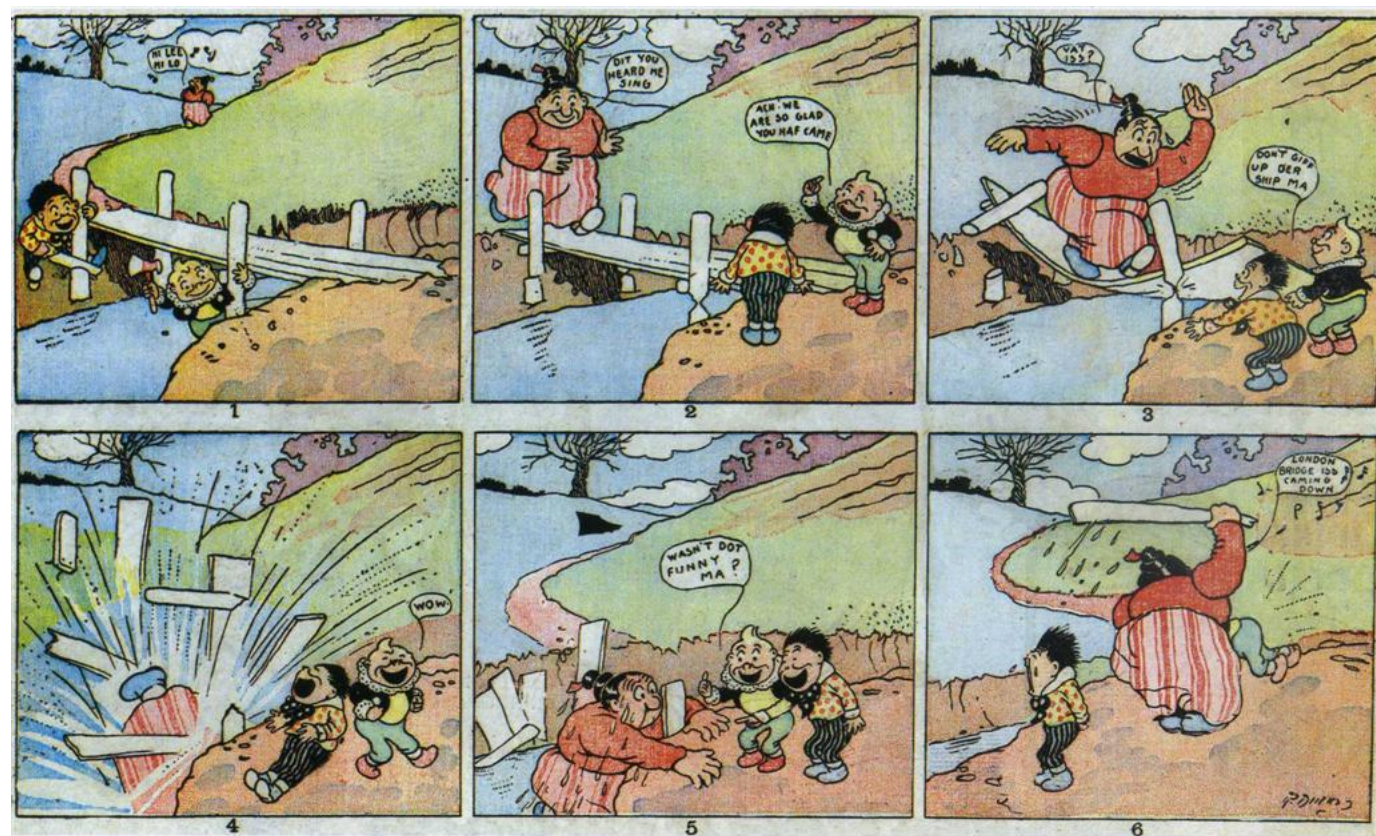

Figura 2: Tira The Katzenjammer Kids inspirada em Mux und Moritz. Imagem de internet. Disponível em: http://www.palmersalmanac.com/uploads/2/3/8/8/23880471/7638770_orig.jpg. Acesso em 10/09/2017.

O livro narra a história de dois moleques terríveis que atormentavam a pequena cidade em que viviam com todo tipo de travessuras. Matavam galinhas, roubavam comida, colocavam pólvora no cachimbo de um desavisado. Busch era conhecido pelas suas obras satíricas e dotadas de todo tipo de violência. Extremamente crítico de instituiçóes como a 
igreja, Busch não poupava esforços em satirizar essas figuras, espetando-as de todas as formas em suas obras (CAMPOS, 2015, p.183). Em Max und Moritz, as crianças servem como um instrumento de sua contestação e, ao mesmo tempo, como resultado de uma sociedade cínica, uma vez que os adultos da cidade simplesmente as jogam no moedor de grãos e dão de comer aos animais como vingança. Não há nenhuma preocupação pedagógica ou lição a ser aprendida. Max und Moritz não tinha as intençóes morais que iriam atormentar, futuramente, pais e mestres sobre o que os filhos estariam lendo.

O sucesso do livro foi tão grande que se tornou a primeira publicação ocidental a ser publicada no Japão na categoria de livro infantil. Anos mais tarde, o mesmo tipo de criança iria aparecer nas tirinhas dos grandes jornais americanos, algumas até mesmo encomendadas para imitar o que Busch havia feito, como é o caso de The Katzenjammer Kids (GARCÍA, 2012, p. 58), no Brasil conhecida como Os Sobrinhos do Capitão. Assim, a infância como o lugar da transgressão seria uma recorrente no modo de representar a criança em tiras de jornais, cunhando uma tradição que se nota até hoje em desenhos animados, por exemplo.

Embora houvesse uma gama de outros temas e personagens que não a criança em outras tiras, o mundo infantil ou o mundo sob os olhos da criança tornou-se uma temática recorrente e extremamente popular. Algumas tiras, como Yellow Kid, tornaram-se rapidamente uma marca registrada, vendendo uma centena de produtos diferentes. Vale ressaltar que nessas primeiras décadas os quadrinhos náo eram, de maneira nenhuma, conhecidos como uma leitura específica para crianças, mas uma leitura popular, para todas as idades, fruto de uma estratégia bem sucedida para vender jornais, evoluindo sua linguagem e seu modo de envolver seus leitores. Todo mundo, de todas as classes e idades, lia as páginas de quadrinhos (MARSCHALL, 1989, p. 13).

Segundo Santiago García (20012, p. 72), o grande sucesso das tiras protagonizadas por crianças acabaram por inclinar o meio para o público infantil. Pouco a pouco, pela constante presença de crianças nas obras, os leitores assimilaram que se tratava de algo produzido para os leitores mirins. No entanto, em um artigo mais completo sobre a questão, Joe Sutliff Sanders (2016) aponta para fatores mais complexos que a constante temática. As tiras publicadas nos suplementos dos jornais eram dirigidas a um público 
misto, pois era de interesse dos donos dos jornais venderem para o maior público possível. Assim, tornava-se inviável direcionar apenas para um público específico como as crianças. Até mesmo os artistas que produziam as tiras entendiam suas obras para um público adulto. $\mathrm{O}$ quadro começa a mudar quando o formato possibilitou novos hábitos de leitura. $\mathrm{O}$ jornal, pelas suas páginas grandes e soltas, era algo a ser lido em conjunto. Após os pais lerem, as crianças reuniam-se em torno das grandes folhas para lerem os comics de que mais gostavam. Tratava-se, portanto, de algo que deveria agradar tanto adultos quanto crianças, afinal de contas, era o pai quem deveria se interessar pelo jornal, a princípio, para comprálo. A chegada do comic book, a revista de quadrinhos, mudou o jogo, alterando público e conteúdo (SANDERS, 2016, p. 14).

O primeiro comic book a ser publicado foi Funnies on Parade, em 1933. Era uma coletânea de tiras já impressas nos jornais, reunidas numa página e grampeadas no meio como um caderninho. Em questão de conteúdo, não trazia nada novo. Seus editores não tinham outra intenção a não ser fornecer a revista gratuitamente, como um brinde publicitário que acompanhava outros produtos. Durante alguns meses, esses caderninhos serviram de peças publicitárias, até que um dos editores, Max Gaines, da Eastern Color Printing Company, percebeu que se tratava de algo vendável e arriscou colocar um selo de 10 cents na capa da Famous Funnies, em 1934, e lançar nas bancas. A partir de entáo, o jogo virou completamente, e os comic books revelaram ser um negócio extremamente lucrativo (GARCÍA, 2012, p. 113, 114).

O preço de dez centavos de dólar era mais barato que o jornal, o bastante para que até crianças pudessem comprar. Assim, os leitores dessas revistas mudaram gradativamente de um público que deveria ser direcionado a outros produtos, considerando que essas publicações serviam antes como brinde para um público que desejava as revistas pelo seu conteúdo. No entanto, o conteúdo ainda era composto de publicaçôes que já haviam circulado nos jornais, o que significa algo para uma audiência diversificada. Quando o negócio dos comic books tornou-se um modelo para outras publicaçóes e a demanda de material a ser publicado aumentou, as revistas procuraram por algo inédito. A partir de então, o conteúdo poderia se moldar ao seu público de interesse (SANDERS, 2016, p.14- 
16). Pouco a pouco, antigos temas das tiras publicadas em jornal vão dando lugar a temas pulp como ficção científica, histórias de terror, western, histórias de detetive, etc. Até que, como filha do gênero $s c i-f i$, surgem as revistas de super-herói.

A consolidação definitiva do formato viria com a publicação da Action Comics 1, em 1938, que trazia ao mundo o Superman, talvez o personagem dos quadrinhos mais famoso da história. O estrondoso sucesso da revista fortalece a indústria e o negócio dos quadrinhos. A temática dos quadrinhos havia mudado. O vagabundo, a família, os casos de conflito entre marido e mulher, a criança travessa, temas tão comuns nas tiras de jornal, transformaram-se em histórias pulps, de apelo aventuresco e contos seriados. Segundo García (2002, p. 116), nos anos 40 e 50 são raros o surgimento de séries importantes na antiga temática das tiras de jornal, pelo menos até Charles Schulz surgir com Peanuts.

Além dos super-heróis e temas pulp, os responsáveis por estabelecer de vez a mentalidade dos quadrinhos como leitura infantil, escreve Sanders (2016, p. 19-24), são os protagonizados por animais falantes, denominados funny animals, gênero que alcançou imensa popularidade e se desenvolveu na indústria de desenhos animados com Walt Disney e Warner Brothers. A partir de então, segundo o autor, a indústria dos quadrinhos definitivamente se entende como algo direcionado diretamente ao público infantil.

No Brasil, o comic book chega através de Adolfo Aizen, com a publicação Mirim, em 1932. Não obteve tanto sucesso quanto os suplementos juvenis que já circulavam, pelo menos de imediato. Após diversas reformulações, caiu nas graças do público resultando na coleção Biblioteca Mirim, que sustentava como anúncio ser "a mais graciosa biblioteca de aventuras para jovens e crianças" (JUNIOR, 2004, p. 67). O modo como os editores anunciavam a coleção evidencia para qual público era direcionada.

Já podemos dizer, portanto, que o meio dos quadrinhos, considerando indústria, leitores, produtos, donos de banca de jornal, entendiam-se, nesse ponto, como algo para crianças. Curioso notar que é a partir dessa mudança de compreensão, quando a sociedade começa a confundir os quadrinhos como uma leitura infantil, que as tiras protagonizadas por crianças saem de cena, dando lugar a personagens mais fantasiosos. Os super-heróis e os funny animals são os que irão habitar o imaginário infantil até os dias de hoje. Superman, 
Batman, Capitão América, Mickey Mouse, Pato Donald, Tom e Jerry etc, acompanharão a maioria das crianças até a fase adulta, seja nos quadrinhos, TV, brinquedos, decoraçóes de festas de aniversário. Os personagens das kid strips, no entanto, não gozarão de tanta permanência no mundo infantil, ainda que sejam personagens reconhecidos como fundamentais dentro da história e tradição dos comics, como Charlie Brown, Os Sobrinhos do Capitão, Calvin e Little Nemo. No Brasil, alguns desses personagens, propriamente os pós Peanuts, como Calvin e Mafalda, entrarão no mundo infantil mais por um esforço didático em utilizá-los em livros escolares do que uma inserção alimentada pelo consumo. A popularidade mundial desses personagens hoje, salvo algumas exceções, deve-se, ainda, a um esforço de intelectuais, artistas, quadrinistas e cartunistas em resgatá-los devido a uma nostalgia e o reconhecimento da peculiaridade dos textos de Schulz, da inventividade e experimentação de McCay em Little Nemo, ou da sagaz anarquia latente em Calvin e Haroldo.

Tal dado nos sugere, no mínimo, que de fato essas tiras não se tratavam de uma leitura infantil simplesmente, embora pudessem ser apreciadas por crianças. Eram, em sua maioria, fruto de um trabalho artístico que se apropriava do universo infantil como uma lente para o mundo. A infância representada pelo artista nas tiras parece servir de palco para comunicar coisas que só por meio daqueles personagens e daquele mundo seria possível.

A escolha da criança como protagonista, para Gatti e Salgado (2013), tem a ver com a imagem que nós, enquanto sociedade, temos da criança.

Afirmam:

A criança está sempre associada ao ser em desenvolvimento, portanto, incompleto. Nesse sentido, pode fazer coisas que os adultos não fariam, dizer coisas que os adultos não diriam. O que ela diz não está atravessado por qualquer mascaramento, náo pode ser associado a algo do obscuro, da falsidade - que seriam típicos da parcela adulta da sociedade -, ela estaria no mesmo patamar dos grandes pensadores (não porque de fato seja, mas porque é criança e, de alguma maneira, está imbuída de um caráter e de uma corporalidade vazios dos vícios do mundo adulto), ela, por ser ingênua e incompleta, pode dizer à altura dos grandes pensadores, "verdades universais", ou coisas que não seriam bem vistas na boca de um adulto, sem que fosse vista como uma indolente[...] (GATTI, SALGADO, 2013, p. 528) 
A pureza e inocência da criança, como um componente de um ser "verdadeiro", não contaminado pelo mundo dos adultos, servem, assim, como um elemento que permite ao artista encerrar no seu personagem um "espírito da verdade". Assim, o infante irá descamar o mundo dos adultos, revirá-lo do avesso, dizer frases inesperadas e desconcertantes, inverter a lógica, atos que não seriam tão genuínos se realizados por um adulto, pois sua inocência seria confundida com tolice e sua sagacidade com cinismo. Estabelece-se, então, um jogo de distanciamento e aproximação do leitor com a criança. Aproxima-se porque esse "avatar" da verdade irá articular nossos anseios profundos, como acontece com o sentimento de fracasso de Charlie Brown, ou o descaso com as regras em Calvin. Mesmo que tenhamos consciência que uma criança jamais articularia angústias tão complexas da vida moderna como Charlie Brown, ou realidades geopolíticas da América Latina como Mafalda, aceitamos porque não se trata de uma criança comum, e sim esse "espírito da verdade" que se distancia de nós. Mas, ao mesmo tempo, ainda é uma criança, e nos aproximamos por que já tivemos infância. Se nas camadas dessas obras encontramos questionamentos sobre as mais diversas nuances do espírito humano, é na superfície que estão postas o que reconhecemos de nossa infância: os problemas escolares, os castigos, as travessuras, o afeto pelos animais de estimação.

Umberto Eco (1970), em seu texto bastante luminoso sobre Peanuts, faz algumas consideraçôes a respeito dos personagens de Schulz e de como tais criaçôes reverberam em nós que, salvo as especificidades temáticas, podem perfeitamente se aplicar as demais kid strips. Diz:

[...] a poesia dessas crianças nasce do fato de que nelas encontramos todos os problemas, todas as angústias dos adultos que estão atrás dos bastidores. [...] Essas crianças nos tocam de perto porque, num certo sentido, são monstros: são as monstruosas reduções infantis de todas as neuroses de um moderno cidadão da civilização industrial. Tocam-nos de perto porque nos damos conta de que, se são monstros, é porque nós, os adultos, as fizemos assim. Nelas encontramos tudo: Freud, a massificação, a cultura absorvida através das várias "Seleçôes", a luta frustrada pelo sucesso, a busca de simpatias, a solidão, a reação proterva, a aquiescência passiva e o protesto neurótico. E no entanto, todos esses elementos não florescem, tal qual os conhecemos, da boca de um grupo de inocentes: são pensados e reditos depois de terem passado pelo filtro da inocência. As crianças de Schulz não são o instrumento malicioso para 
contrabandear os nossos problemas de adultos; esses problemas são nelas vividos segundo os modos de um psicologia infantil, e justamente por isso nos parece tocantes e sem esperança, como se de repente reconhecêssemos que os nosso males poluíram tudo, até à raiz. (ECO, 1970, p. 286,287)

A relação de aproximação e distanciamento que temos com esses personagens perpassa a condição dessas criaçôes. Como diz Eco, são monstros, mas também possuem o poético como parte de sua natureza. Embora Eco esteja escrevendo especificamente sobre Peanuts, os elementos que nunca florescem dizem algo não só sobre essa obra em específico, mas são perceptíveis em grande parte das kids strips como forma de composição. São sempre variaçôes do mesmo tema, problemas que jamais serão resolvidos de maneira definitiva. Os personagens estáo condenados a reviver as mesmas situaçóes, indagar sobre os mesmos assuntos, sem jamais experimentar uma mudança significativa. Não haverá catarse cujo resultado será a metamorfose. A criança não aprenderá uma lição que a transformará para sempre, como se não tivesse passado ou futuro. Ela é o que é, para sempre e continuamente, o instrumento do artista para comunicar sua visão sobre o mundo.

Há mais camadas nessas tiras de jornal do que sugere a ideia do senso comum ao vincular aos quadrinhos a categoria de infantil. Tal associação da indústria do comic book a uma leitura estritamente infantil resultou em uma série de equívocos e problemas que acabaram por acachapar o meio em preocupaçóes pedagógicas a despeito das possibilidades que os quadrinhos forneciam. Talvez o maior problema tenha sido o encabeçado pelo Dr. Fredric Wertham ao publicar, em 1954, Seduction of the inocent, uma obra que acusava os quadrinhos de serem catalisadores da delinquência juvenil. Wertham mirava todo tipo de quadrinho, dos super-heróis aos quadrinhos de terror, condenando qualquer conteúdo que mencionasse ou fizesse alusão a temas adultos como sexo, violência, drogas, etc. Álvaro de Moya (1970) relembra o relato de Jules Feiffer, quadrinista norte-americano, em que toda essa "sujeira" citada por Wertham era imperceptível aos olhos das crianças da época, pois essas mesmas histórias, hoje, são relembradas como sinais da inocência juvenil, e não da delinquência. O que estava contaminado, assim, era o olhar do mundo adulto (MOYA, 1970, p. 73). 
Fredric Wertham convenceu uma geração inteira de pais e mestres que os quadrinhos eram uma coisa ruim para seus filhos. Uma verdadeira caça às bruxas foi instaurada com direito a fogueiras públicas de inúmeros exemplares. O que estava entranhado agora na concepção da sociedade não era apenas que os quadrinhos eram má leitura para os filhos, mas também que se tratavam apenas e exclusivamente de uma leitura para as crianças e, por isso, temas adultos não deveriam existir.

A associação dos comics, como uma leitura infantil, fez com que os quadrinhos acabassem por compartilhar de algumas questôes da literatura destinada às crianças. Preocupaçóes pedagógicas em detrimento do poético subestimam a capacidade de leitura e acesso das crianças a esses textos. O Comics Code ${ }^{2}$, o código de censura dos quadrinhos que surgiu a partir das cruzadas do Dr. Wertham, é fruto desse problema. Dos anos cinquenta ao final dos sessenta, os quadrinhos norte-americanos renderam-se ao desejo pedagógico de imaginarem uma vida moralmente correta para os seus filhos. As histórias dos super-heróis tornaram-se bobas e comportadas. Algo que só mostraria sinais de mudança com os quadrinhos Marvel e, posteriormente, mudaria de forma definitiva com o cenário underground com a influência dos comics, quadrinhos que não tinham o menor pudor em tratar sobre a vida real, sexo, drogas e etc.

O fato de quadrinhos terem sido por muito tempo entendidos como uma leitura infantil, e que um adulto ler e colecionar seria algo visto como imaturidade (o que nunca incomodou os aficionados dessa arte, na verdade) mostra-se uma incompreensão fruto do racionalismo dos tempos modernos. A ideia de que ser adulto é gostar de coisas adultas, e coisas adultas são sempre sérias e tratam de assuntos cinzas e sem graça é uma ferramenta de mutilação dos sentidos, uma vez que se perde a capacidade de apreciar (e por que não produzir?) o humor da arte. C. S. Lewis (2009), em seu ensaio Três maneiras de se escrever para crianças, disserta sobre um fazer poético que, embora seja sobre literatura, muito se aplica aos quadrinhos que tenham crianças como protagonistas, ou apresente temática que os coloque na posição de infantil. Diz:

\footnotetext{
${ }^{2}$ Devido ao clamor moralista, as editoras norte-americanas, na década de 50, criaram o Comics Code Authority, um código de autocensura dos quadrinhos que impediam que obras que fugissem aos critérios estabelecidos pelo código fossem distribuídas.
} 
Nos casos em que a história para crianças é simplesmente a forma adequada para o que o autor quer dizer, é evidente que os leitores que quiserem ouvir o que ele tem a dizer vão ler ou reler a história, seja qual for a idade deles. [...] Inclino-me quase a afirmar como regra que uma história para crianças de que só as crianças gostam é uma história ruim. As boas permanecem. Uma valsa da qual você só gosta enquanto está dançando não é uma boa valsa. (LEWIS, 2009, p. 743)

O pensamento de Lewis expressa de forma precisa o que ocorre com os leitores dos quadrinhos. Os aficionados por essa arte a descobrem na infância e a continuam apreciando mesmo depois de adultos, pois não se trata de uma valsa que se gosta apenas quando está dançando. Os leitores de quadrinhos carregarão consigo este hábito talvez por toda vida, pois talvez seja o caso dos próprios autores de quadrinhos não estarem preocupados em criar algo que seja destinado apenas às crianças, mas sim interessados na arte mesma dos quadrinhos. Histórias como as desenvolvidas por Carl Barks, que trabalhou na família pato da Disney, desenvolvendo personagens como Tio Patinhas, Pato Donald, Huguinho, Zezinho e Luizinho e todos os habitantes de Patópolis, são hoje consideradas verdadeiros clássicos na história dos quadrinhos, obras fundamentais que influenciam ainda cartunistas e quadrinistas de qualquer gênero. Talvez considerar quadrinhos como coisa de criança seja um equívoco, mas quem sabe se trata de um equívoco desimportante. Que importa que os personagens da Disney sejam animais falantes apetecíveis ao gosto infantil? Se as histórias de Carl Barks possuem a capacidade de nos emocionar e, não só isso, são capazes de garantir a linguagem dos quadrinhos no campo da arte, então sim, temos um equívoco desimportante.

\section{REFERÊNCIAS}


CAMPOS, Rogério de. Imageria: o nascimento das histórias em quadrinhos. São Paulo: Veneta, 2015.

ECO, Umberto. Apocalípticos e Integrados. Trad. Pérola de Carvalho. São Paulo: Perspectiva, 1970.

GARCÍA, Santiago. A Novela Gráfica. Trad. Magda Lopes. São Paulo: Martins Fontes, 2012.

GATTI, Márcio Antônio; SALGADO, Luciana Salazar. Personagens infantis de tiras cômicas em suportes diversos: uma questão de circulaçâo, aforizaçâo e estereotipia. In: DELTA, Sáo

Paulo, v. 29, p. 517-534, 2013. Disponível

em: http://www.scielo.br/scielo.php?script=sci_arttext\&pid=S0102-

44502013000300009\&lng=en\&nrm=iso Acesso em 26/08/2016

HARVEY, Robert C. Children of the Yellow Kid - The evolution of the American Comic Strip. Seattle: University of Washington, 1998.

JUNIOR, Gonçalo. A guerra dos gibis: a formação mercado editorial brasileiro e a censura aos quadrinhos, 1933-64. São Paulo: Companhia das Letras, 2004.

LEWIS, C. S. Três maneiras de escrever para crianças. In: As Crônicas de Nárnia. Trad. Paulo Mendes Campos, Silêida Steuernagel. São Paulo: Martins Fontes, 2009.

MARSCHALL, Richard. America's great comic-strip artists. New York: Abbeville, 1989.

MOYA, Álvaro de. Era uma vez um menino amarelo. In: Shazam! São Paulo: Contexto, 1970.

SANDERS, Joe Sutliff. How comics became kid's stuff. In.: ABATE, Michelle A.; SANDERS, Joe S. (Org) Goodgrief! Children and Comics. Columbus, OH: Billy Ireland Cartoon Library \&Museum, 2016. E-book. Disponível em: <https://kb.osu.edu/dspace/bitstream/handle/1811/77539/BICLM_Good-Grief_6-92016.pdf?sequence $=1>$ Acesso em 22/09/2016.

SCHNEIDER, Matthias. Max und Moritz, 1865, Wilhelm Busch. In.: GRAVETT, Paul (Editor geral). 1001 comics you must read before you die. New York: Quintessence: 2011, p. 31.

WERTHAM, Fredric. Excerpt from Seduction of the Innocent. In.: HEER, Jeet; WORCESTER, Kent. (Org) A comics studies reader. Jackson, MS: University Press of Mississipi, 2009. Versão Kindle. 